\title{
Optimal Multiobjective Design of Hybrid Active Power Filters Considering a Distorted Environment
}

\begin{abstract}
The development of new passive, active and hybrid filtering techniques is important, and the issues of higher quality, reduced complexity, higher efficiency, and lower cost are important conditions that need to be addressed with regard to the expected stringent trends in power quality obligations. This paper suggests a new approach for the optimal sizing of hybrid active power filter (HAPF) parameters, presented for three-phase industrial power systems. Hybrid filter topology can be used to compensate harmonic currents as well as for power factor corrections, without concern for importing and exporting harmonics, or simply the series and parallel resonance that may occur. The new trend in harmonic power filter design is not to obtain the best solution from a single objective optimization, but to obtain a good compromise solution accomplished under other conflicting objectives. FORTRAN Feasible Sequential Quadratic Programming (FFSQP) is used to determine the proposed filter optimal sizing to minimize the total voltage harmonic distortion as the main objective function, where maintaining the load power factor at an acceptable limit is desired. If the total harmonic voltage distortion achieves the specified goal, then the objective is redirected into minimizing the resultant voltage and current total harmonic distortions. The optimal design of the HAPF is analyzed by means of three case studies.
\end{abstract}

Index Terms-Hybrid power filters, Optimization, Power quality, Power system harmonics.

\section{NOMENCLATURE}

$\mathrm{R}_{\mathrm{LH}}, \mathrm{X}_{\mathrm{LH}}$

$\mathrm{G}_{\mathrm{LH}}, \mathrm{B}_{\mathrm{LH}}$

$\mathrm{R}_{\mathrm{SH}}, \mathrm{X}_{\mathrm{SH}}$

G

$\mathrm{V}_{\mathrm{H}}$

$\mathrm{X}_{\mathrm{L}}, \mathrm{X}_{\mathrm{C}}$

$\mathrm{I}_{\mathrm{SH}}$

$\mathrm{I}_{\mathrm{S}}$

$\mathrm{I}_{\mathrm{LH}}$

$\mathrm{I}_{\mathrm{L}}$

$\mathrm{V}_{\mathrm{LH}}$

$\mathrm{V}_{\mathrm{SH}}$

$V_{L}$
$V_{S}$
$P_{L}$
$P_{S}$

RMS value of the load voltage (line-toneutral) in volts

RMS value of the supply voltage (line-toneutral) in volts

Load active power per phase in watts

Supply active power per phase in watts

\section{INTRODUCTION}

The exponential growth of harmonic pollution has become more serious recently due to the wide use of nonlinear loads, which result in an obvious degradation of power quality. These problems have different effects on all electrical sectors, ranging from minor variations in power up to bringing whole factories to a standstill [1]-[3].

Proposed early stage harmonic compensation techniques provide different solutions for the proper limitation of harmonic disturbance levels, and among the various techniques used to reduce these harmonic disturbances, the most employed are tuned passive filters, due to their simplicity and different frequency response characteristics that can be accomplished with a certain harmonic filtering objective, in addition to their economic cost. Accordingly, the actual technical and economic approach for harmonic suppression is through the use of passive filters [4]-[6].

However, the latent danger in their practical operation is very serious. The filtering effectiveness of conventional passive filters depends on the source impedance, which has previously not been determined accurately. Further problems include importing harmonics by the series resonance with source impedance, or the possibility of hidden risks due to parallel resonance between the source impedance and the passive filter at a specific frequency; thus, exporting hazards to the entire system, and causing distortion in the voltage at the point of common coupling (PCC). In addition, the configured passive filter components, such as the inductance and/or the capacitance, are not durable against tuning frequency variations. Therefore, there is great concern about their manufacturing tolerance [7].

On the other hand, active filters are more reliable than passive filters, exhibiting better performance whilst at the same time avoiding most of the problems that occur in passive facilities [8]. Unfortunately, complexity, difficult maintenance, and the higher cost of active facilities compared with traditional passive facilities have been sensed in the power quality markets, delaying their widespread deployment in a broad sense. Thus, the cheapest facility for power factor correction and harmonic mitigation is still the passive facility [9].

Consequently, in the last twenty years, since the early 
1990s, topology combining passive and active facilities has been developed. This combination partially solves the problem of high cost associated with the active power filter, because the size or the rating of the active filter used in the hybrid power filter is much smaller than that used with pure active filter techniques, whilst maintaining the properties necessary to solve the problems caused by passive filters, and removing the resonance that may occur. Despite the beneficial development added by hybrid power filter technology, the most managed solution for power factor correction is still the passive facility, because of the complex design of the hybrid topology compared with the passive facility. For example, the selection of the gain value of the hybrid active filter is usually a matter of trial and error. Some begin with the power converter gain equaling one or any other value according to the filter type, but it will be commonly noted that better performance is obtained with other gain values, especially when considering source and load nonlinearities, making active or hybrid filter design difficult when guessing the initial feasible values for its parameters. In other words, achieving hybrid filter parameters, performance, and interaction with the utility grid at a programmable optimization level is not as simple as with passive filters [10]-[13].

Any harmonic filter design must achieve the optimal solution whilst satisfying many objectives; generally, these objectives might conflict with each other. An important substitute for multiobjective optimization is not to obtain the best solution, but to obtain a good compromise solution [14]. In this paper, a suggested hybrid power filter design is investigated, using the FFSQP optimization package to determine the optimum values for the filter parameters represented in its inductance, capacitance (elements of its tuned passive portion), and gain, in order to reduce total harmonic voltage distortion (VTHD) at the PCC in the power system to an acceptable level, regardless of the source impedance, and also to improve the load power factor to a desired value $(90 \% \leq \mathrm{PF} \leq 95 \%)$. If the VTHD achieves the specified value, while complying with the other constraints, then the objective becomes the minimization of both the resultant voltage and current total harmonic distortion. The technical merits of the proposed hybrid active filter (HAPF) are discussed and analyzed in various case studies, considering source and load nonlinearities.

In this paper, a series-type hybrid filter is introduced as a series combination of passive filters and an active filter (without introducing a matching transformer). As the series capacitor sustains the fundamental component of the grid voltage, the active filter can be operated with a very low DC bus voltage, which is the significant advantage of reducing both the rated kVA capacity and the switching ripples. Additionally, to reduce the overshoot current in the capacitor, a small inductance should be in series with the capacitor.

The compensation performances are greatly affected by the gain value $(G)$ and other passive filter parameters ( $L$ and $C$ ); if the gain is small, the passive filtering will be dominant and the conventional problems of passive filters will appear because of the decrease in the hybrid filter bandwidth. This leads some to say that the total current harmonic distortion (ITHD) decreases if the gain increases and larger gains improve the hybrid filter compensation performance.

Finally, if the passive elements are not properly selected, the active filter gain must be substantially increased to maintain the same compensation performance. Thus, the optimal choice of the three variables $(\mathrm{C}, \mathrm{L}$ and $\mathrm{G})$ is treated as a nonlinear programming problem. Therefore, the main contribution of this paper can be summarized as using an optimization method to ascertain the optimal hybrid active filter gain value and other passive parameters, in order to overcome the observed difficulties in the hybrid filter design when guessing the initial feasible values of the parameters.

The optimization package FFSQP is chosen from among the many sequential quadratic programming packages for the proposed optimal design because of its advantages. It has the ability to achieve an improvement in solution accuracy, provides convergence to the global solution, and is considered to be a well-built and rapid method for solving minimization or maximization of nonlinear optimization problems, subject to general constraints [6], [15]-[16].

\section{HYBRID POWER FILTERS FOR HARMONIC COMPENSATION}

Figure 1 shows the system configuration of the hybrid compensation required for harmonic suppression and reactive power compensation for an industrial power system. The hybrid active power filter is based on a three-phase voltagesource power converter, using IGBT switches connected in parallel with the utility grid, and a set of tuned filters or simply a single tuned filter according to the system requirements [17]. The tuned filter is used to decrease the capacity of the power converter, which enables the active power filter to be used in a high-power situation [18].

The voltage-source converter is usually used rather than the current-source converter because it has higher efficiency, lower cost, and is smaller in size than the current converter. Moreover, reference [8] clarifies that the IGBT module is more suitable for the voltage-source converter because a freewheeling diode is connected in antiparallel with each IGBT. This means that the IGBT does not need to provide the capability of reverse blocking in itself; thus, bringing more flexibility to the device design with a compromise among conducting and switching losses and short-circuit capability, than with reverse-blocking IGBT.

The power converter of the hybrid power filter is established to mitigate the flowing harmonic current. It improves the filtering characteristic of its tuned filter by injecting a voltage harmonic waveform at its terminals proportional to the harmonic component of the supply current with amplitude equal to

$$
\mathrm{V}_{\mathrm{H}}=\mathrm{G}^{*} \mathrm{I}_{\mathrm{SH}}
$$

The active power filter is considered to be a controlled voltage source $\mathrm{V}_{\mathrm{H}}$, where $(\mathrm{G})$ is the controlled gain of the dependent source, and it is designed to equal zero at the fundamental frequency; in other words, it acts as a virtual harmonic resistor in series with the mains impedance at the harmonic frequency causing enlargement in the impedance, 
and hence, the power converter can suppress the harmonic current due to the virtual harmonic resistor inserted [17]-[18]. This means that the hybrid power filter performance can be controlled by adjusting the gain value, causing a notable reduction in the total harmonic distortion (ITHD) of the source current. Because of the series combination of passive and active filters, a considerable reduction of inverter power rating is achieved by decreasing both the line current and line-to-line voltage. In this topology, the fundamental frequency component voltage drops on the capacitor of the passive filter as it presents high reactance for low frequencies. At higher frequencies, the voltage drop on the capacitor is low. As the fundamental component voltage drops on the capacitor, the inverter has to work against a lower line voltage (dominant fundamental frequency component). This means that the required voltage rating of the inverter is significantly reduced.

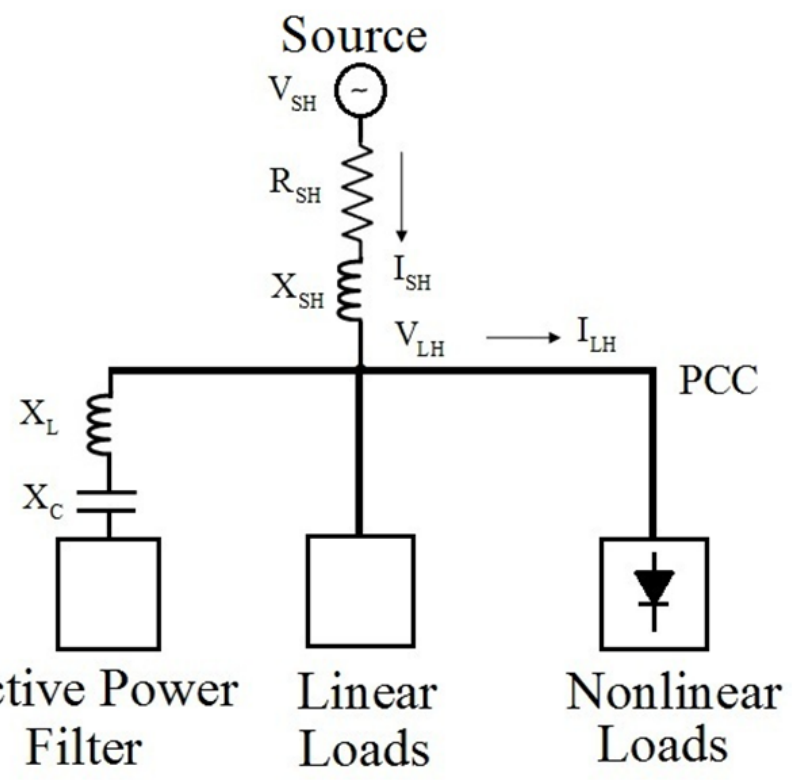

Fig.1. System configuration of the proposed hybrid compensation

This topology performs well, while considering load nonlinearity. However, a more complicated situation occurs when considering both source and load nonlinearities, because this often involves various conflicting objectives and constraints; therefore, sequential quadratic programming is used.

\section{COMPENSATED SySTEM CONFIGURATION}

In the proposed system, a controlled voltage source, representing a conventional active power filter, is connected in series with a single tuned passive filter, as in Figure 2, for a power system feeding a harmonic-current type nonlinear load.

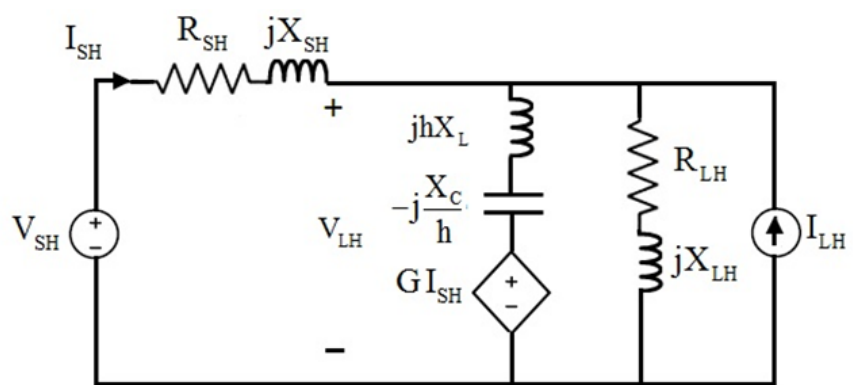

Fig.2. Single phase equivalent circuit for the proposed HAPF for harmonic current source

Recalling reference [6], the Thevenin voltage source representing the utility supply voltage and the harmonic current source representing the nonlinear load are:

$$
\begin{aligned}
& \mathrm{v}_{\mathrm{S}}(\mathrm{t})=\sum_{\mathrm{h}} \mathrm{v}_{\mathrm{SH}}(\mathrm{t}) \\
& \mathrm{i}_{\mathrm{L}}(\mathrm{t})=\sum_{\mathrm{h}} \mathrm{i}_{\mathrm{LH}}(\mathrm{t})
\end{aligned}
$$

The hth harmonic Thevenin source impedance is

$$
\mathrm{Z}_{\mathrm{SH}}=\mathrm{R}_{\mathrm{SH}}+\mathrm{j} \mathrm{X}_{\mathrm{SH}}
$$

and the hth harmonic load impedance is:

$$
\mathrm{Z}_{\mathrm{LH}}=\mathrm{R}_{\mathrm{LH}}+\mathrm{j} \mathrm{X}_{\mathrm{LH}}
$$

or by admittance:

$$
\mathrm{Y}_{\mathrm{LH}}=\mathrm{G}_{\mathrm{LH}}-\mathrm{jB} \mathrm{B}_{\mathrm{LH}}
$$

The model shown is satisfactory where the VTHD is less than ten percent [19].

After some derivations for the studied system shown in Figure 2, the main compensated system indices analyzing the system performance would be as follows.

The compensated utility supply current $\left(\mathrm{I}_{\mathrm{SH}}\right)$ is given as:

$$
I_{S n}=\frac{\left[V_{S n} R_{L n}+I_{L n} R_{C}\right]+j\left[V_{S n}\left(X_{L n}+X_{F n}\right)+I_{L n} X_{C}\right]}{\left[R_{T L n}+G_{L n}+R_{C}-X_{S n} X_{F n}\right]+j\left[X_{T L n}+G_{L n}+X_{C}+R_{S n} X_{F n}\right]}
$$

The compensated load voltage $\left(\mathrm{V}_{\mathrm{LH}}\right)$ is given as:

$$
\mathrm{V}_{\mathrm{LH}}=\frac{E+j F}{C+j D}
$$

where:

$$
\begin{aligned}
& \mathrm{A}=\mathrm{V}_{\mathrm{SH}} \mathrm{R}_{\mathrm{LH}}-\mathrm{I}_{\mathrm{LH}} \mathrm{X}_{\mathrm{LH}} \mathrm{X}_{\mathrm{FH}}, \\
& \mathrm{B}=\left[\mathrm{V}_{\mathrm{SH}}\left(\mathrm{X}_{\mathrm{LH}}+\mathrm{X}_{\mathrm{FH}}\right)+\mathrm{I}_{\mathrm{LH}} \mathrm{R}_{\mathrm{LH}} \mathrm{X}_{\mathrm{FH}}\right] \text {, } \\
& \mathrm{C}=\mathrm{R}_{\mathrm{TLH}}+\mathrm{GR}_{\mathrm{LH}}-\left(\mathrm{X}_{\mathrm{LH}}+\mathrm{X}_{\mathrm{SH}}\right) \mathrm{X}_{\mathrm{FH}} \text {, } \\
& \mathrm{D}=\mathrm{X}_{\mathrm{TLH}}+\mathrm{GX}_{\mathrm{LH}}+\left(\mathrm{R}_{\mathrm{LH}}+\mathrm{R}_{\mathrm{SH}}\right) \mathrm{X}_{\mathrm{FH}} \text {, } \\
& \mathrm{E}=\mathrm{V}_{\mathrm{SH}}\left(\mathrm{GR}_{\mathrm{LH}}-\mathrm{X}_{\mathrm{LH}}\left(\mathrm{hX_{ \textrm {L } }}-\frac{\mathrm{X}_{\mathrm{C}}}{\mathrm{h}}\right)\right)+\mathrm{I}_{\mathrm{LH}} \mathrm{X}_{\mathrm{TLH}}\left(\mathrm{hX_{ \textrm {L } }}-\frac{\mathrm{X}_{\mathrm{C}}}{\mathrm{h}}\right), \\
& \mathrm{F}=\mathrm{V}_{\mathrm{SH}}\left(\mathrm{R}_{\mathrm{LH}}\left(\mathrm{hX_{ \textrm {L } }}-\frac{\mathrm{X}_{\mathrm{C}}}{\mathrm{h}}\right)+\mathrm{GX}_{\mathrm{LH}}\right)-\mathrm{I}_{\mathrm{LH}} \mathrm{R}_{\mathrm{TLH}}\left(\mathrm{hX_{ \textrm {L } }}-\frac{\mathrm{X}_{\mathrm{C}}}{\mathrm{h}}\right) .
\end{aligned}
$$

so that:

$$
\begin{aligned}
& \mathrm{R}_{\mathrm{TLH}}=\mathrm{R}_{\mathrm{SH}} \mathrm{R}_{\mathrm{LH}}-\mathrm{X}_{\mathrm{LH}} \mathrm{X}_{\mathrm{SH}}, \\
& \mathrm{X}_{\mathrm{TLH}}=\mathrm{R}_{\mathrm{LH}} \mathrm{X}_{\mathrm{SH}}+\mathrm{R}_{\mathrm{SH}} \mathrm{X}_{\mathrm{LH}} .
\end{aligned}
$$

Because of the inverse proportionality between the gain $(\mathrm{G})$ 
and the compensated utility supply current $\left(\mathrm{I}_{\mathrm{SH}}\right)$, as shown in (6), increasing the gain $G$ to much larger values results in a reduction in the source impedance effect on the filtering characteristics of the passive filter; thus, reducing the source harmonic current to its minimum value.

Additionally, no amplification occurs in the harmonic current at the different resonant frequencies because the active filter acts as a damping resistance [18]. On the other hand, this situation does not agree with the compensated load voltage, as shown in (7). Other system performance indices can be given by:

The compensated load power factor (PF):

$$
\mathrm{PF}=\frac{\mathrm{P}_{\mathrm{L}}}{\mathrm{V}_{\mathrm{L}} \mathrm{I}_{\mathrm{S}}}=\frac{\sum_{\mathrm{h}} \mathrm{G}_{\mathrm{LH}} \mathrm{V}_{\mathrm{LH}}^{2}}{\sqrt{\sum_{\mathrm{h}} \mathrm{I}_{\mathrm{SH}}^{2} \sum_{\mathrm{h}} \mathrm{V}_{\mathrm{LH}}^{2}}}
$$

Also, the compensated load displacement power factor (Dpf):

$$
\text { Dpf }=\frac{\mathrm{P}_{\mathrm{L} 1}}{\mathrm{~V}_{\mathrm{L} 1} \mathrm{I}_{\mathrm{S} 1}}
$$

where subscript ' 1 ' represents the fundamental component.

The transmission losses $\left(\mathrm{P}_{\mathrm{LOSS}}\right)$ :

$$
\mathrm{P}_{\text {LOSS }}=\sum_{\mathrm{h}} \mathrm{I}_{\mathrm{SH}}^{2} \mathrm{R}_{\mathrm{SH}}
$$

The transmission efficiency $(\eta)$ :

$$
\eta=\frac{\mathrm{P}_{\mathrm{L}}}{\mathrm{P}_{\mathrm{S}}}=\frac{\sum_{\mathrm{h}} \mathrm{G}_{\mathrm{LH}} \mathrm{V}_{\mathrm{LH}}^{2}}{\sum_{\mathrm{h}} \mathrm{I}_{\mathrm{SH}}^{2} \mathrm{R}_{\mathrm{SH}}+\sum_{\mathrm{h}} \mathrm{G}_{\mathrm{LH}} \mathrm{V}_{\mathrm{LH}}^{2}}
$$

The compensated VTHD at the load terminals:

$$
\mathrm{VTHD}=\frac{\sqrt{\sum_{\mathrm{h} \succ 1} \mathrm{~V}_{\mathrm{LH}}^{2}}}{\mathrm{~V}_{\mathrm{L} 1}}
$$

Similarly, the ITHD for the utility supply current is given as:

$$
\mathrm{ITHD}=\frac{\sqrt{\sum_{\mathrm{h} \succ 1} \mathrm{I}_{\mathrm{SH}}^{2}}}{\mathrm{I}_{\mathrm{S} 1}}
$$

Usually, current distortion is much higher than the voltage distortion. This mirrors the basic concern of IEEE 519-1992, in which the higher ITHD reflects the VTHD, leading to its increase [6].

This idea leads some to define harmonic pollution as a function of ITHD; however, according to [20], the harmonic pollution formula (HP) can be approximated and given by:

$$
H P=\sqrt{V T H D^{2}+I T H D^{2}}
$$

The fitness of the power harmonic filters for both harmonic currents and voltages can be evaluated from such a measurement.

\section{CONSTRAINTS AND OBJECTIVE FUnCTION FORMULATION}

Most research papers introduce a predetermined filter feedback gain and then build all the system performance on it. Additionally, the effect of increasing gain on the utility harmonic current distortion and on the resonance, which may occur between the supply and the passive elements, are usually discussed under the condition of sinusoidal supply voltage. Reference [21] presented a new method based on the limitation of the gain value to certain values due to the stability problems of the system.

This paper introduces a different topology in which there is no pre-determination of the filter feedback gain, but a search for the optimum, which leads to the optimum results required, whilst taking into account compliance with IEEE Standard 519-1992 for harmonic currents. The constraints may be detailed as follows [22]:

A) Source nonlinearity

Represented in the source harmonic currents as $\left(\mathrm{I}_{\mathrm{SH}}\right)$ and voltages as $\left(\mathrm{V}_{\mathrm{SH}}\right)$.

B) Load nonlinearity

Represented in harmonic load currents as $\left(\mathrm{I}_{\mathrm{LH}}\right)$ and voltages as $\left(\mathrm{V}_{\mathrm{LH}}\right)$.

C) IEEE Standard 519-1992

According to IEEE 519-1992, VTHD for voltage level up to $69 \mathrm{kV}$ is less than or equal to $5.0 \%$.

Also, ITHD should be limited to a standard percent according to the system $\left(\mathrm{I}_{\mathrm{SC}} / \mathrm{I}_{\mathrm{L}}\right)$ ratio.

D) Load power factor

Maintaining a given load power factor at a specified range is desired, $90 \% \leq \mathrm{PF} \leq 95 \%$.

E) Parameter constraints

The hybrid active power filter (HAPF) compensator parameters $\left(\mathrm{X}_{\mathrm{C}}, \mathrm{X}_{\mathrm{L}}\right.$, and $\left.\mathrm{G}\right)$ are manipulated as continuously constrained to lie between specified bounds. The selected numerical value ranges are given in ohms as:

- $0.00 \leq \mathrm{G} \leq 20.00$,

- $0.00 \leq \mathrm{X}_{\mathrm{C}} \leq 10.00$,

- $0.00 \leq \mathrm{X}_{\mathrm{L}} \leq 1.00$.

Thus, the object functions considered in the optimal design of the HAPF complying with the former constraints are presented as follows:

Minimize VTHD $\left(\mathrm{X}_{\mathrm{C}}, \mathrm{X}_{\mathrm{L}}, \mathrm{G}\right)$

subject to:

- $\operatorname{VTHD}\left(\mathrm{X}_{\mathrm{C}}, \mathrm{X}_{\mathrm{L}}, \mathrm{G}\right) \leq 5 \%$.

- $90 \% \leq \mathrm{PF}\left(\mathrm{X}_{\mathrm{C}}, \mathrm{X}_{\mathrm{L}}, \mathrm{G}\right) \leq 95 \%$.

If the VTHD achieves the specified value whilst complying with the other constraints, the objective function is redirected into minimizing both the resultant voltage and current total harmonic distortion with parameter values $\left(\mathrm{X}_{\mathrm{C}}{ }^{*}, \mathrm{X}_{\mathrm{L}}{ }^{*}, \mathrm{G}^{*}\right)$ imported from the VTHD local minimum parameters as follows:

Minimize $H P\left(X_{C}, X_{L}, G\right)$

subject to:

$$
\text { - }\left(X_{\mathrm{C}}, \mathrm{X}_{\mathrm{L}}, \mathrm{G}\right) \in\left(\mathrm{X}_{\mathrm{C}}{ }^{*}, \mathrm{X}_{\mathrm{L}}{ }^{*}, \mathrm{G}^{*}\right)
$$

\section{Optimization Technique AND The SEARCh Algorithm}

Recently, references [6] and [16] examined FFSQP search codes in the field of harmonic power filters, and the general search formulation was attractive because of the simplicity of the sequential approximation in replacing the given nonlinear problem by a sequence of sub problems that are more easily 
solved. The most important property of the FFSQP method is the reduced computation time needed to guarantee convergence to the global solution, even if the initial guess proposed by the user is infeasible for some inequality and/or equality constraint [15].

The summary of the proposed search algorithm is demonstrated below:

1. Determine the specifications of the FFSQP subroutine and construct the necessary subroutines to develop the FFSQP [15]; specify the lower and upper bounds for each parameter in the ranges previously demonstrated.

2. Substitute the values of $X_{C}, X_{L}$ and $G$ into the objective function, and calculate the minimum VTHD, whilst complying with the constraints.

3. Run the search algorithm considering the last values of filter parameters to be the initial values tested at the beginning of each search.

4. The algorithm will stop when a feasible point is reached or when the stop criterion is achieved; this criterion is the relative variation $(\varepsilon)$ in the objective function, and it is defined in the search algorithm as:

$$
\varepsilon \leq 10^{-8}
$$

5. After stopping, scan through the local minimums satisfying the constraints.

6. Calculate the local minimums of the HP corresponding to the predetermined local minimums of VTHD.

7. Scan through them in order to ascertain the global solution.

8. Determine the compensator parameter values corresponding to the global solution. Use the obtained optimum values to evaluate some other functions that explain the system performance when installing the proposed filter.

\section{CASE STUdies AND RESUltS}

Three case studies of an industrial plant (Table I) were simulated using the FFSQP optimization method. The numerical data were taken from an example in IEEE publications [22], where the inductive three-phase loads are $5100 \mathrm{~kW}$ and $4965 \mathrm{kVAR}$ with a displacement load power factor of $71.65 \%$. The 60 -cycle supply bus voltage is $4.16 \mathrm{kV}$ (2400 volt line-to-neutral). The short-circuit capacity is 80 MVA. The source and load harmonics were assumed to be time-invariant quantities and were chosen arbitrarily to have more harmonic content than present in many previous publications [6], [19]. Also, the load and source resistances are assumed to be frequency independent, such that $\left(\mathrm{R}_{\mathrm{LH}}=\mathrm{R}_{\mathrm{L}}\right.$ and $\mathrm{R}_{\mathrm{SH}}=\mathrm{R}_{\mathrm{S}}$ ) [6].

Table II shows the uncompensated system results to be defined and compared with the HAPF compensation results. For the uncompensated system, the existence of a small harmonic current can cause very high voltage distortion, as shown in Case 1 for the clean utility voltage source.

The system under study has been analyzed for different configurations that show the system performance with the HAPF installed. Table III shows the proposed technique providing an efficient system performance, resulting in: a reduction of the utility supply current, a lower transmission loss, higher transmission efficiency, higher displacement power factor, and higher load power factor than in the uncompensated system cases shown in Table II. Furthermore, Table IV summarizes the results indicating the percentage of improvement in the main indices with reference to the uncompensated system results, illustrating system performance with the HAPF installed. Additionally, Table V shows the system behavior when a random guess of the variables under consideration is implemented for Case 3.

TABLE I

Three Case Studies of AN Industrial Plant [6]

\begin{tabular}{c|c|c|c}
\hline \hline Parameters and cases & Case 1 & Case 2 & Case 3 \\
\hline $\mathrm{R}_{\mathrm{S} 1}(\Omega)$ & 0.02163 & 0.02163 & 0.02163 \\
\hline $\mathrm{X}_{\mathrm{S} 1}(\Omega)$ & 0.2163 & 0.2163 & 0.2163 \\
\hline $\mathrm{R}_{\mathrm{L} 1}(\Omega)$ & 1.7421 & 1.7421 & 1.7421 \\
\hline $\mathrm{X}_{\mathrm{L} 1}(\Omega)$ & 1.696 & 1.696 & 1.696 \\
\hline $\mathrm{V}_{\mathrm{S} 1}(\mathrm{kV})$ & 2.40 & 2.40 & 2.40 \\
\hline $\mathrm{V}_{\mathrm{S} 5}\left(\% \mathrm{~V}_{\mathrm{S} 1}\right)$ & 0.00 & 2.00 & 4.00 \\
\hline $\mathrm{V}_{\mathrm{S} 7}\left(\% \mathrm{~V}_{\mathrm{S} 1}\right)$ & 0.00 & 1.50 & 3.00 \\
\hline $\mathrm{V}_{\mathrm{S} 11}\left(\% \mathrm{~V}_{\mathrm{S} 1}\right)$ & 0.00 & 1.00 & 2.00 \\
\hline $\mathrm{V}_{\mathrm{S} 13}\left(\% \mathrm{~V}_{\mathrm{S} 1}\right)$ & 0.00 & 0.50 & 1.00 \\
\hline $\mathrm{I}_{\mathrm{L} 5}\left(\% \mathrm{I}_{\mathrm{L}}\right)$ & 40.00 & 40.00 & 40.00 \\
\hline $\mathrm{I}_{\mathrm{L} 7}\left(\% \mathrm{I}_{\mathrm{L}}\right)$ & 6.00 & 6.00 & 6.00 \\
\hline $\mathrm{I}_{\mathrm{L} 11}\left(\% \mathrm{I}_{\mathrm{L}}\right)$ & 2.00 & 2.00 & 2.00 \\
\hline $\mathrm{I}_{\mathrm{L} 13}\left(\% \mathrm{I}_{\mathrm{L}}\right)$ & 1.00 & 1.00 & 1.00 \\
\hline \hline
\end{tabular}

TABLE II

UNCOMPENSATED SYSTEM RESULTS IN THE THREE CASES

\begin{tabular}{c|c|c|c}
\hline \hline Parameters and cases & Case 1 & Case 2 & Case 3 \\
\hline $\mathrm{PF}(\%)$ & 65.99 & 65.95 & 65.87 \\
\hline $\mathrm{I}_{\mathrm{S}}(\mathrm{A})$ & 989.01 & 989.40 & 989.83 \\
\hline $\mathrm{Dpf}(\%)$ & 71.65 & 71.65 & 71.65 \\
\hline $\mathrm{V}_{\mathrm{L}}(\mathrm{V})$ & 2277.01 & 2277.59 & 2279.68 \\
\hline$\eta(\%)$ & 98.60 & 98.60 & 98.59 \\
\hline $\mathrm{P}_{\mathrm{LOSS}}(\mathrm{kW})$ & 21.16 & 21.17 & 21.19 \\
\hline $\mathrm{ITHD}(\%)$ & 38.62 & 38.74 & 38.87 \\
\hline VTHD (\%) & 17.47 & 17.62 & 18.15 \\
\hline HP $(\%)$ & 42.39 & 42.56 & 42.90 \\
\hline \hline
\end{tabular}

TABLE III

RESUlts IN THE THREE CASES FOR THE OPTIMIZATION PROCESS FOR THE HAPF

\begin{tabular}{c|c|c|c}
\hline \hline Parameters and cases & Case 1 & Case 2 & Case 3 \\
\hline $\mathrm{X}_{\mathrm{C}}(\Omega)$ & 2.7279 & 2.7061 & 2.6171 \\
\hline $\mathrm{X}_{\mathrm{L}}(\mathrm{m} \Omega)$ & 122.14 & 97.93 & $0.99 * 10^{-6}$ \\
\hline $\mathrm{G}(\Omega)$ & 11.00 & 12.00 & 8.07 \\
\hline $\mathrm{PF}(\%)$ & 95.00 & 95.00 & 95.00 \\
\hline $\mathrm{Dpf}(\%)$ & 95.00 & 95.03 & 95.15 \\
\hline $\mathrm{I}_{\mathrm{S}}(\mathrm{A})$ & 753.84 & 753.54 & 752.90 \\
\hline $\mathrm{V}_{\mathrm{L}}(\mathrm{V})$ & 2430.08 & 2430.80 & 2431.59 \\
\hline$\eta(\%)$ & 99.30 & 99.30 & 99.29 \\
\hline $\mathrm{P}_{\mathrm{LOSS}}(\mathrm{kW})$ & 12.47 & 12.73 & 19.53 \\
\hline $\mathrm{ITHD}(\%)$ & 0.54 & 0.81 & 3.98 \\
\hline $\mathrm{VTHD}(\%)$ & 0.29 & 2.73 & 4.44 \\
\hline HP $(\%)$ & 0.61 & 2.85 & 5.97 \\
\hline \hline
\end{tabular}

TABLE IV

PERCENTAGE OF IMPROVEMENT REFERRED TO THE UNCOMPENSATED SYSTEM IN THE THREE CASES

\begin{tabular}{|l|l|l|l|l}
\hline Parameters and cases & Status & Case 1 & Case 2 & Case 3 \\
\hline
\end{tabular} 


\begin{tabular}{c|c|c|c|c}
\hline \hline PF (\%) & Increases by & 43.96 & 44.05 & 44.22 \\
\hline Dpf (\%) & Increases by & 32.59 & 32.63 & 32.80 \\
\hline$\eta(\%)$ & Increases by & 0.71 & 0.71 & 0.71 \\
\hline P $_{\text {LOSS }(\mathrm{kW})}$ & Decreases by & 41.07 & 39.87 & 7.83 \\
\hline ITHD (\%) & Decreases by & 98.60 & 97.91 & 89.76 \\
\hline VTHD (\%) & Decreases by & 98.34 & 84.51 & 75.54 \\
\hline HP (\%) & Decreases by & 98.56 & 93.3 & 86.08 \\
\hline \hline
\end{tabular}

TABLE V

RANDOM GUESSES OF VARIABLES UNDER STUDY: CASE 3

\begin{tabular}{c|c|c|c}
\hline \hline Parameters & Guess 1 & Guess 2 & Guess 3 \\
\hline $\mathrm{X}_{\mathrm{C}}(\Omega)$ & 3.50 & 2.6170 & 2.50 \\
\hline $\mathrm{X}_{\mathrm{L}}(\mathrm{m} \Omega)$ & 100 & 0.01 & 500 \\
\hline $\mathrm{G}(\Omega)$ & 1.00 & 2.00 & 3.00 \\
\hline $\mathrm{PF}(\%)$ & 98.93 & 94.67 & 78.98 \\
\hline $\mathrm{Dpf}(\%)$ & 99.97 & 95.85 & 81.03 \\
\hline$\eta(\%)$ & 99.20 & 99.29 & 99.00 \\
\hline $\mathrm{P}_{\mathrm{LosS}}(\mathrm{kW})$ & 20.99 & 39.33 & 120.26 \\
\hline ITHD $(\%)$ & 14.30 & 15.59 & 20.31 \\
\hline VTHD $(\%)$ & 2.38 & 2.68 & 11.30 \\
\hline HP $(\%)$ & 14.50 & 15.82 & 23.24 \\
\hline
\end{tabular}

It is clear that the fitted filter causes a significant reduction in the HP percent. This can be considered a good sign for the capability of the proposed hybrid power filter in harmonic mitigation. Thus, the quality of the electrical system can be improved considerably. The HAPF has a compromise capability in suppression of the harmonic voltage distortion below the standard limits in all cases, as shown in Table III, for the VTHD percent of the compensated load voltage. Additionally, Figures 3 and 4 show the values of the load harmonic voltage components before and after compensation in Cases 1 and 3, respectively. It is obvious that the resultant values are all well within standard limits.

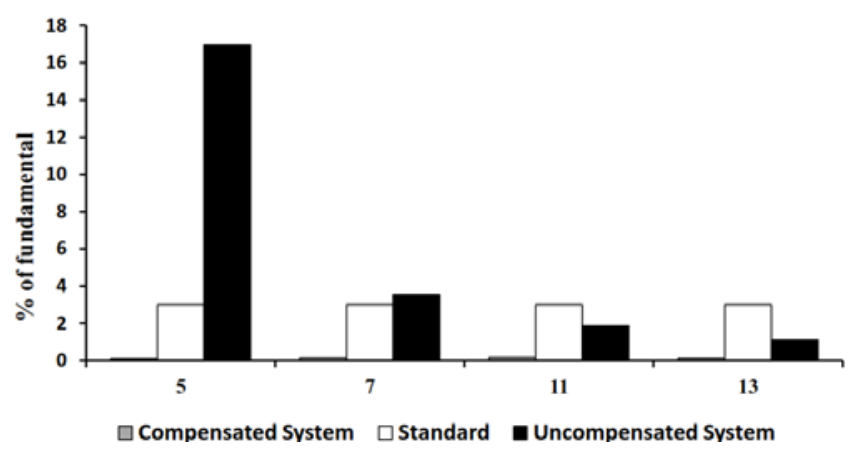

Fig.3. Harmonic content of the load voltage before and after compensation: Case 1

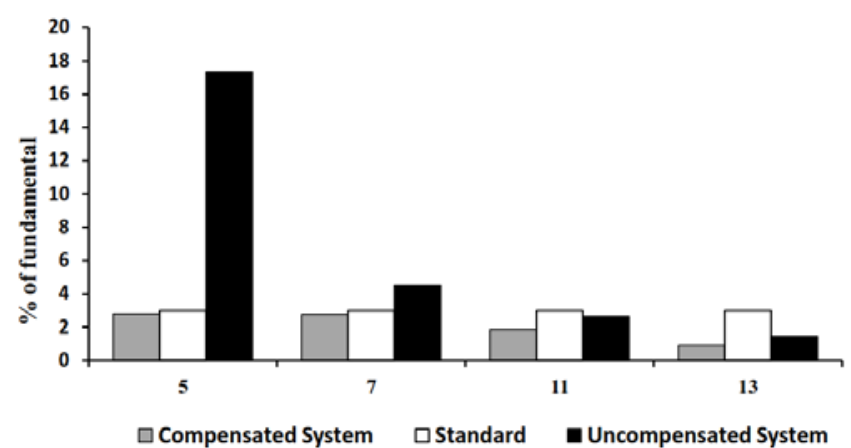

$\square$ Compensated System $\square$ Standard Uncompensated System
Fig.4. Harmonic content of the load voltage before and after compensation: Case 3

Moreover, the demonstrated method comprises less HP of the supply current, compared with the conventional power filters, whilst maintaining the quality of voltage in its acceptable limits when considering supply nonlinearities. The total harmonic current distortion value of the compensated supply current is dramatically reduced to a very reasonable limit. Figures 5 and 6 show the values of the supply current harmonic content before and after compensation in Cases 1 and 3 , respectively.

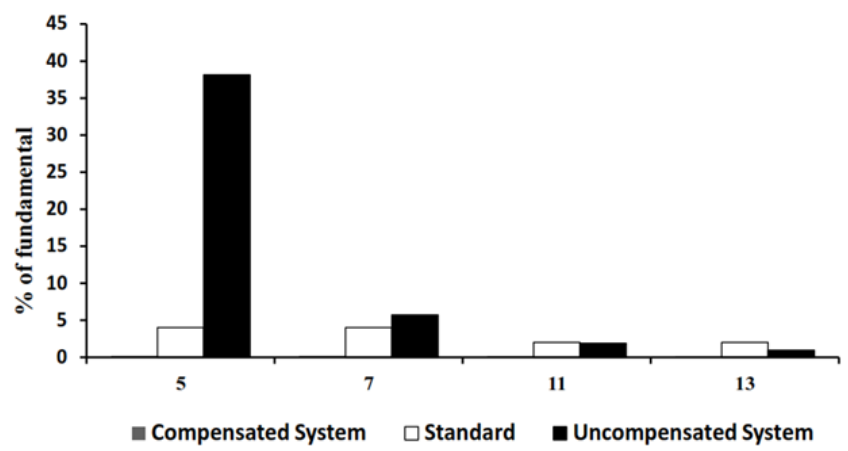

Fig.5. Harmonic content of the supply current before and after compensation:

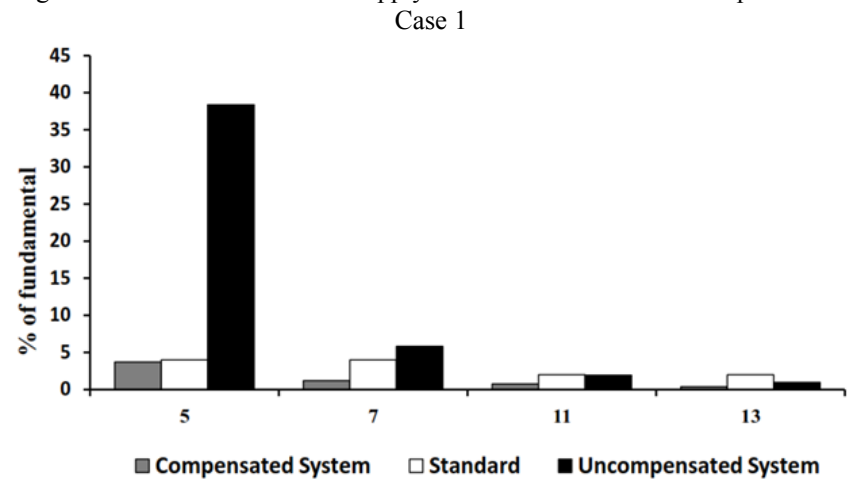

Fig.6. Harmonic content of the supply current before and after compensation: Case 3

Comparing Tables III and V, it is evident that a random guess of the variables can converge to the optimal solution, as shown in Guess 1, and only a change in the gain will be required. Also, it can diverge from the optimal solution, or fall in the resonance region, as shown in Guess 3.

As shown in Table III, it is obvious for equal short-circuit capacity systems with additional utility voltage harmonic content, that a higher HP ratio will be observed at the PCC. Thus, there are higher transmission losses, higher RMS load voltages, and higher load VTHD levels because of the increase in the harmonic content with respect to the fundamental component. Also, higher transmission voltage drop and increase in the active load power consumption will be noted, which represents additional loading for the network. As a normal reaction, overall transmission efficiency will decrease. Additionally, because the proposed system consists of a small rated voltage-source active power filter in series with a passive filter connected to each phase, no additional switching filter is required for the current ripples. 
The hybrid filter bandwidth can be modified by changing the active power filter gain, and larger values of gain $(G>12)$ improve the hybrid filter compensation performance [23], [24]. Figure 7 shows the effect of increasing the active power filter gain on VTHD, ITHD, and HP in the nonlinear problem in Case 3, complying with the pre-specified constraints, all at a load power factor approximately equal to $95 \%$. It is observed that higher values of gain improve the hybrid filter compensation capability, especially for the mitigation of current distortion percentage, validating that the ITHD of the supply current decreases if the gain increases [25], [26]. However, Figure 7 indicates that no significant improvement is obtained for greater values of gain if it is not related to the VTHD variation.

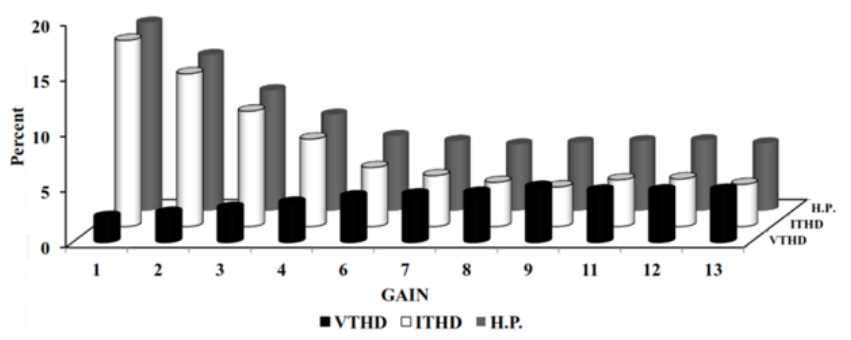

Fig.7. VTHD, ITHD, and HP versus active power filter gain: Case 3

Finally, if the passive elements are not properly selected, the active filter gain must be substantially increased to maintain the same compensation performance. Also, if the active power filter gain is not properly chosen, poorer system performance might occur, especially when considering high supply voltage distortion. To avoid this difficulty, it is necessary to report the change in the active power filter gain with VTHD and ITHD to guarantee better system performance.

\section{CONCLUSION}

In recent years, much attention has focused on simplifying the frequently used solutions concerning harmonic contamination associated with low load power factors in power networks supplying nonlinear loads. Different solutions have been proposed to improve and synopsize the practical utilization of harmonic filters. Selection of an adequate solution requires some knowledge of the different topologies to ensure that it is the appropriate solution for the specified goal, both technically and economically.

In this paper, the proposed power filter mitigates both current and voltage HP more effectively than other methods. The selection of the optimal HAPF parameters is manipulated as a multiobjective optimization problem. The main contribution of this paper is in demonstrating a simple procedure for estimating the optimal parameters of the HAPF before the beginning of its experimental application in order to save time and effort.

Finally, three cases were studied; the results discussed the effect on system performance of increasing the supply harmonic voltage levels for a weak short-circuit capacity system. The simulated results validate the effectiveness and the robustness of the proposed design procedure.

\section{REFERENCES}

[1] R. L. de Araujo Ribeiro, C. C. de Azevedo, and R. M. de Sousa, "A Robust Adaptive Control Strategy of Active Power Filters for PowerFactor Correction, Harmonic Compensation, and Balancing of Nonlinear Loads," IEEE Trans. Power Electronics, vol. 27, no. 2, pp. 718-730, Feb. 2012.

[2] H. Wen, Z. Teng, Y. Wang, and X. Hu, "Spectral Correction Approach based on Desirable Sidelobe Window for Harmonic Analysis of Industrial Power System," IEEE Trans. Ind. Electron., in press.

[3] M. T. Elmathana, A. F. Zobaa, and S. H. E. Abdel Aleem, "Economical design of multiple-arm passive harmonic filters for an industrial firm - case study," $15^{\text {th }}$ International Conference on Harmonics and Quality of Power, ICHQP 2012, Hong Kong, June 17-20, 2012. Paper ID: 0103.

[4] D. Lamar, J. Sebastian, M. Arias, and A. Fernandez, "On the Limit of the Output Capacitor Reduction in Power-Factor Correctors by Distorting the Line Input Current," IEEE Trans. Power Electronics, vol. 27, no. 3, pp. 1168-1176, Mar. 2012.

[5] A. M. Al-Zamil, and D. A. Torrey, "A passive series, active shunt filter for high power applications," IEEE Trans. Power Electronics, vol.16, no. 1, pp.101-109, Jan. 2001.

[6] S. H. E. Abdel Aleem, A. F. Zobaa and M. M. Abdel Aziz, "Optimal C-Type Passive Filter Based on Minimization of the Voltage Harmonic Distortion for Nonlinear Loads," IEEE Trans. Ind. Electron., vol. 59, no.1, pp. 281-289, Jan. 2012.

[7] Z. Chen, and Y. Luo, "Low-harmonic-input three-phase rectifier with passive auxiliary circuit: comparison and design consideration," IEEE Trans. Ind. Electron., vol. 58, no.6, pp. 2265-2273, June 2011.

[8] H. Akagi, "New trends in active filters for power conditioning," IEEE Trans. Ind. App., vol. 32, no. 6, pp. 1312-1322, Nov. 1996.

[9] J. He, Y. Li, and M. S. Munir, "A Flexible Harmonic Control Approach through Voltage-Controlled DG Grid Interfacing Converters," IEEE Trans. Ind. Electron., vol. 59, no. 1, pp. 444-455, Jan. 2012.

[10] P. Jintakosonwit, H. Fujita, H. Akagi, and S. Ogasawara, "Implementation and Performance of Cooperative Control of Shunt Active Filters for Harmonic Damping Throughout a Power Distribution System," IEEE Trans. Ind. Appl., vol. 39, no. 2, pp. 556564, Mar./Apr. 2003.

[11] M. Rivera, J. Rodriguez, B. Wu, J. R. Espinoza, and C. A. Rojas, "Current Control for an Indirect Matrix Converter With Filter Resonance Mitigation," IEEE Trans. Ind. Electron., vol. 59, no. 1, pp. 71-79, Jan. 2012.

[12] Y. Tang, P. Loh, P. Wang, F. Choo, and F. Gao, "Exploring Inherent Damping Characteristic of LCL-Filters for Three-Phase GridConnected Voltage Source Inverters," IEEE Trans. Power Electronics, vol. 27, no. 3, pp. 1433-1443, Mar. 2012.

[13] Z. Zhao, Y. Zhong, H. Gao, L. Yuan and T. Lu, "Hybrid Selective Harmonic Elimination PWM for Common-Mode Voltage Reduction in Three-Level Neutral-Point-Clamped Inverters for Variable Speed Induction Drives," IEEE Trans. Power Electron., vol. 27, no. 3, pp. 1152-1158, Mar. 2012

[14] Y. P. Chang, and C. J. Wu, "Optimal Multiobjective Planning of Large-scale Passive Harmonic Filters using Hybrid Differential Evolution Method Considering Parameter and Loading Uncertainty," IEEE Trans. Power Del., vol. 20, no. 1, pp. 408-416, Jan. 2005.

[15] J. L. Zhou, A. L. Tits, and C. T. Lawrence, User's guide for FFSQP version 3.7: A FORTRAN code for solving optimization problems, possibly minimax, with general inequality constraints and linear equality constraints, generating feasible iterates, TR-92-107r5, Institute for Systems Research, University of Maryland, College Park, MD20742, USA, 1997.

[16] A. F. Zobaa, M. M. Abdel-Aziz, and S. H. E. Abdel Aleem, "Comparison of Shunt-passive and Series-passive Filters for DC Drive Loads," Electric Power Components \& Systems, vol. 38, no. 3, pp. 275-291, Mar. 2010.

[17] H. L. Jou, J. C. Wu, K. D. Wu, M. S. Huang, and C. A. Lin, "A Hybrid Compensation System Comprising Hybrid Power Filter and AC Power Capacitor," Electric Power Energy System Journal, vol. 28, no. 7, pp. 448-458, Sep. 2006. 
[18] F. Z. Peng, H. Akagi, and A. Nabae, "A New Approach to Harmonic Compensation in Power Systems - A Combined System of Shunt Passive and Series Active Filters," IEEE Trans. Ind. Applications, vol. 26, no. 6, pp. 983-990, Nov./Dec. 1990.

[19] A. F. Zobaa, "A New Approach for Voltage Harmonic Distortion Minimization," Electric Power Systems Research Journal, vol. 70, no. 3, pp. 253-260, Aug. 2004.

[20] IEEE standard definitions for the measurement of electric power quantities under sinusoidal, balanced, or unbalanced conditions, IEEE Standard 1495-2010, 2010.

[21] L. Sainz and J. Balcells, "Harmonic Interaction Influence Due to Current Source Shunt Filters in Networks Supplying Nonlinear Loads," IEEE Trans. Power Del., vol.27, no.3, pp.1377-1385, Jul. 2012.

[22] IEEE Recommended Practices and Requirements for Harmonic Control in Electrical Power Systems, IEEE Standard 519-1992, 1992.

[23] M. Z. El-Sadek, Power Systems Harmonic Filters, 1st ed., vol. 1. Muktar Press, Assiut, Egypt, 2007.

[24] R. Inzunza, and H. Akagi, "A 6.6-kV Transformerless Shunt Hybrid Active Filter for Installation on a Power Distribution System," IEEE Trans. Power Electron., vol. 20, no. 4, pp. 893-900, Jul. 2005.

[25] F. Milano, "Hybrid Control Model of under Load Tap Changers," IEEE Trans. Power Del., vol.26, no.4, pp.2829-2837, Oct. 2011.

[26] N. Yousefpoor, S. H. Fathi, N. Farokhnia, and H. A. Abyaneh, "THD Minimization Applied Directly on the Line-to-Line Voltage of Multilevel Inverters," IEEE Trans. Ind. Electron., vol. 59, no. 1, pp. 373-380, Jan. 2012. 